\title{
DO ASSET-DEMAND FUNCTIONS OPTIMIZE OVER THE MEAN AND VARIANCE OF REAL RETURNS? A SIX-CURRENCY TEST
}

\author{
Jeffrey FRANKEL \\ Department of Economics, University of California, Berkeley, CA 94720, USA \\ Charles M. ENGEL \\ Department of Economics, University of Virginia, Charlottesville, VA 2290I, USA
}

Received July 1983, revised version received January 1984

\begin{abstract}
International asset demands are functions of expected returns. Optimal portfolio theory tells us that the coefficients in this relationship depend on the variance-covariance matrix of real returns. But previous estimates of the optimal portfolio (1) assume expected returns constant and (2) are not set up to test the hypothesis of mean-variance optimization. We use maximum likelihood estimation to impose a constraint between the coefficients and the error variancecovariance matrix. For a portfolio of six currencies, we are able statistically to reject the constraint. Evidently investors are either not sophisticated enough to maximize a function of the mean and variance of end-of-period wealth, or else are too sophisticated to do so.
\end{abstract}

\section{Introduction}

Investors are thought to balance their portfolios among the assets of various countries as functions of the expected rates of return. What determines the parameters in these functions? The most promising source of enlightenment is finance theory. Under the hypothesis that investors optimize with respect to the mean and variance of end-of-period wealth, the parameters are seen to depend in a simple way on the variance-covariance matrix of returns and on the degree of risk-aversion. ${ }^{1}$

The hypothesis of mean-variance optimization has not been adequately tested empirically. A number of studies have taken the empirical techniques for estimating the Capital Asset Pricing Model (CAPM) that have been developed for other financial markets, and have extended them to foreign currencies. $^{2}$ But, as noted by Dumas (1982), many of these studies are not set

${ }^{1}$ The field was pioneered by Kouri (1976, 1977), Solnik (1974), and Grauer, Litzenberger and Stehle (1976). The results have recently been reformulated in a manner simple enough for direct use in macroeconomic models by Dornbusch (1983), with an amendment by Krugman (1981). Other recent contributions include Adler and Dumas (1976, 1983), Frankel (1979), Fama and Farber (1979), Garman and Kohlhagen (1980), Stulz (1981), and Hodrick (1981).

Examples are Roll and Solnik (1977), Cornell and Dietrich (1978), Kouri and de Macedo (1978), de Macedo (1982), and Dornbusch (1980). For references to the standard CAPM tests, and for a well-known critique of them, see Roll (1977).

0022-1996/84/\$3.00 (C) 1984, Elsevier Science Publishers B.V. (North-Holland) 
up as tests of the hypothesis that actual asset-demand functions are in fact of the mean-variance optimizing form. By making use of data on net asset supplies, the present paper is able to test the hypothesis explicitly.

Another problem with most previous empirical finance studies is that they make the assumption that the expected returns perceived by investors are constant over time. This assumption is made, often implicitly, in order to be able to estimate the expected returns from the unconditional ex post sample mean. But the assumption is not appropriate for a macro model. It would imply that the arguments of the asset-demand functions, as opposed to the parameters of the functions, are constant over time. It is an essential element of most macro models that expected returns be allowed to vary.

A few recent studies do allow expected returns to change over time, but only gradually, as a function of past returns. Two estimates of the optimal portfolio, von Furstenberg (1981) and de Macedo, Goldstein and Meerschwam (1982), estimate expected returns from the time series of actual returns as in the technique of 'rolling regressions'. Hansen and Hodrick (1983) resembles the present paper in that it is explicitly a test of the optimization hypothesis. But it considers the market or 'benchmark' portfolio to be unobservable; so instead of trying to measure the return directly, the paper uses as instrumental variables lagged values of the relative returns on the various currencies.

In the present paper expected returns are allowed to vary freely. Ex post rates of return are related to the asset supplies by an equation in which the error term is identified as the market's expectational error. ${ }^{3}$ The hypothesis that the functions are optimizing can be implemented by imposing the constraint that the coefficient matrix is proportional to the variancecovariance matrix of the error term, and estimating by maximum likelihood (MLE). If the optimizing hypothesis were true, the constrained MLE estimates would be the most efficient estimates of the parameters. Moreover, one can test the hypothesis by comparing the likelihood when the parameters are estimated subject to this constraint to the likelihood when they are estimated unconstrained. Our finding is that a likelihood ratio test rejects the constraint of mean-variance optimization. This evidence suggests that market agents are either not sophisticated enough to maximize their end-of-period wealth with regard to mean and variance, or else perhaps are more sophisticated than this, maximizing instead a more complicated intertemporal function.

This paper continues past work by the authors. There are two important new features. First, we extend the test of mean-variance optimization to a portfolio of six nominal assets: marks, pounds, yen, French francs, Canadian dollars, and U.S. dollars. Dumas (1982, p. 5) and many other authors have

\footnotetext{
${ }^{3}$ Examples of studies that attempt to relate returns to asset supplies without imposing all constraints of mean-variance optimization are Dooley and Isard (1983), Frankel (1982a), and Kasliwal (1982).
} 
emphasized the importance of looking at 'a reasonably complete list of individual assets available across the world'. Of course, it would be desirable to include equities and all other assets, but data difficulties inevitably put a limit on the number of assets we can consider.

Second, we use price data to measure real returns explicitly, thus allowing for inflation risk, rather than treating the exchange rate as the only stochastic variable. ${ }^{4}$ As Kouri and de Macedo (1978, p. 118) have emphasized, "rational lenders and borrowers are presumably concerned with the real values of their assets and liabilities, and hence the purchasing power of a currency over goods and services available in the world economy is the appropriate standard of its value'. The price for allowing stochastic inflation rates is that we are not able to allow consumption preferences to differ among investors residing in different countries. We assume, rather, that all investors have the same preferences and thus can be aggregated together. ${ }^{5}$

Section 2 of this paper shows how asset-demand functions can be estimated, without imposing the constraint of mean-variance optimization. Section 3 derives theoretically the optimizing form of the functions. Section 4 estimates the asset-demand functions subject to the constraint that they are indeed of this form, and does the likelihood ratio test. Section 5 draws conclusions. Details of the data calculations are available in an appendix to Frankel (1982b).

\section{Estimation of unconstrained asset-demand functions}

In this paper we assume that investors allocate their portfolio among assets denominated in six currencies. We define a column vector of five portfolio shares:

$$
x_{t}^{\prime} \equiv\left[x_{t}^{\mathrm{DM}} x_{t}^{\mathrm{f}} x_{t}^{\mathrm{Y}} x_{t}^{\mathrm{F}} x_{t}^{\mathrm{CS}}\right]
$$

${ }^{4}$ Frankel (1982b, 1983) treat only the exchange rates as stochastic. The (1983) paper differs further from the present one by restricting the assets to two: marks and dollars. The (1982b) paper differs from the present one by imposing the optimization hypothesis, and thus obtaining more efficient estimates of the parameters, rather than testing the hypothesis. Among previous studies of the optimal portfolio, Kouri and de Macedo (1978), de Macedo (1980), and de Macedo, Goldstein and Meerschwam (1982) have allowed for stochastic price levels. Among joint tests of market efficiency and risk-neutrality, Frenkel and Razin (1980) and Engel (1982) have allowed for stochastic price levels.

${ }^{5}$ Among theoretical models, some like Grauer, Litzenberger and Stehle (1976), Fama and Farber (1979), and Frankel (1979) assume that all investors consume a common basket of goods; others, like Solnik (1974), assume that investors of each country consume only their own goods; while still others, like Kouri (1976) and Dornbusch (1983), allow investors of each country to consume baskets that include foreign goods but that are more heavily weighted toward their own goods. The last framework is adopted in Frankel (1982b, 1983). Since data on asset supplies are available only in aggregate form, not broken down by holder, differing asset-demand functions have to be aggregated before they can be estimated. When all investors share the same source of uncertainty, the exchange rate, this can be done, using data on the distribution of wealth, as in those two papers. When prices of national goods are stochastic as well, as in the present paper, the aggregation is not possible. 
The residual is the share allocated to U.S. dollars: $\left(1-x_{t}^{\prime} l\right)$, where $t$ is a column vector of five ones. The asset-demand function gives us the demands as a function of the expected rates of return on the assets relative to the numeraire asset, the dollar:

$$
x_{t}=\alpha+\beta\left(E_{t} r_{t+1}-l E_{t} r_{t+1}^{S}\right)
$$

where $E_{t} r_{t+1}^{s}$ is the expected real return on dollar assets, $E_{t} r_{t+1}$ is a column vector of the expected real returns on the other five assets, $\beta$ is a matrix of coefficients, and $\alpha$ is a vector of intercepts. We will show in the next section that the linear form (1) is correct if agents are mean-variance optimizing. But the important point is that at this stage we are not constraining the parameters in $\alpha$ and $\beta$ to be anything in particular. They could be based on investors' arbitrary 'tastes' for assets as easily as on mean-variance optimization. Of course we have already restricted the function somewhat; for example, many macroeconomic models include real income levels, representing a transactions demand for the assets.

In the past, the stumbling block in econometric estimation of portfoliobalance equations has been the measurement of expected returns. We do not wish to assume that they are constant, or that they are some ad hoc function of past returns. Such a formulation would not allow expected returns to change suddenly, for example in response to central bank intervention or in response to other new information. The solution adopted here is to invert eq. (1), so that expected returns are viewed as depending on asset supplies:

$$
E_{t} r_{t+1}-\imath E_{t} r_{t+1}^{S}=-\beta^{-1} \alpha+\beta^{-1} x_{t}
$$

To deal with the unobservability of expectations, we make the assumption that investors form them rationally. The ex post relative return $\left(r_{t+1}+i r_{t+1}^{s}\right)$, which is observable, is assumed equal to the expected return plus a random error term $\varepsilon_{t+1}$. By 'random', we mean uncorrelated with all information $I_{t}$ available at the beginning of the period over which the return is measured:

$$
r_{t+1}-t r_{t+1}^{s}=E_{t} r_{t+1}-\imath E_{t} r_{t+1}^{s}+\varepsilon_{t+1}, \quad E\left(\varepsilon_{t+1} \mid I_{t}\right)=0 .
$$

Substituting (2) into (3):

$$
r_{t+1}-t r_{t+1}^{s}=-\beta^{-1} \alpha+\beta^{-1} x_{t}+\varepsilon_{t+1}
$$

The parameters of eq. (4) can now be estimated by regression. The regression error is simply the expectational error $\varepsilon_{t+1}$, which we know to be uncorrelated with the right-hand-side variables by the assumption of rational expectations. 
At first thought, it might seem that the components of the right-hand-side variables - the asset quantities or, at least, the asset prices - must be endogenous. But the existence of other equations that determine these variables does not in itself mean that the error term is correlated with the variables. Owing to the special nature of the rational expectations assumption, the error term will still be uncorrelated with the right-hand-side variables, as long as the asset-demand function specified in eq. (1) holds exactly. The assumption that there are no omitted variables or measurement error in eq. (1) is admittedly a strong one. ${ }^{6}$

Table 1 reports regressions of the system of eqs. (4). Only one or two coefficient estimates in each equation are significantly different from zero. Of those, the two diagonal elements, which are the only ones on which we have a priori information, are of the incorrect sign: an increase in the supply of Canadian dollars or marks appears to induce a decline, rather than an increase, in the expected future returns on these two assets. On the other hand, we are able to reject with a likelihood ratio test the constraint that all coefficients are zero. The log-likelihood for the five unconstrained equations taken together is 1086.49, whereas the constrained log-likelihood is only 1057.11. (Twice the difference is distributed $\chi^{2}$ with 25 degrees of freedom.)

One assumption that we have already made is borne out. The absence of serial correlation in the error term is established by Durbin-Watson statistics and Box-Pierce $Q$ statistics for lag lengths of 12 months (reported) and fewer (not reported). The absence of serial correlation supports the hypothesis of rational expectations.

The main lesson to be drawn from table 1 is the low degree of precision that plagues estimation of general portfolio-balance equations, and the need to bring additional information to bear. This provides the motivation for considering the constraints placed on the parameters by the hypothesis, developed in the following section, that they are derived from mean-variance optimization by investors. If one believes this hypothesis, then the resulting estimates will be more precise.

\section{Derivation of asset-demand functions from mean-variance optimization}

In this section we derive the correct form for the asset demands of an investor who maximizes a function of the mean and variance of his end-of-

\footnotetext{
${ }^{6}$ As always, omitted variables or measurement errors would render the estimates biased and inconsistent. These considerations justify, at a minimum. special care in the calculation of the asset supply variables, described in the data appendix available in Frankel (1982b). Very briefly, the net supply of assets denominated in a country's currency is calculated as the cumulation of that country's government debt, corrected for three factors: (1) debt issued in foreign currency, (2) foreign exchange intervention by the country's central bank (inferred from data on international reserve holdings by correcting for valuation changes), and (3) foreign cxchange intervention in the domestic currency by other countries' central banks (a factor often neglected in empirical studies).
} 


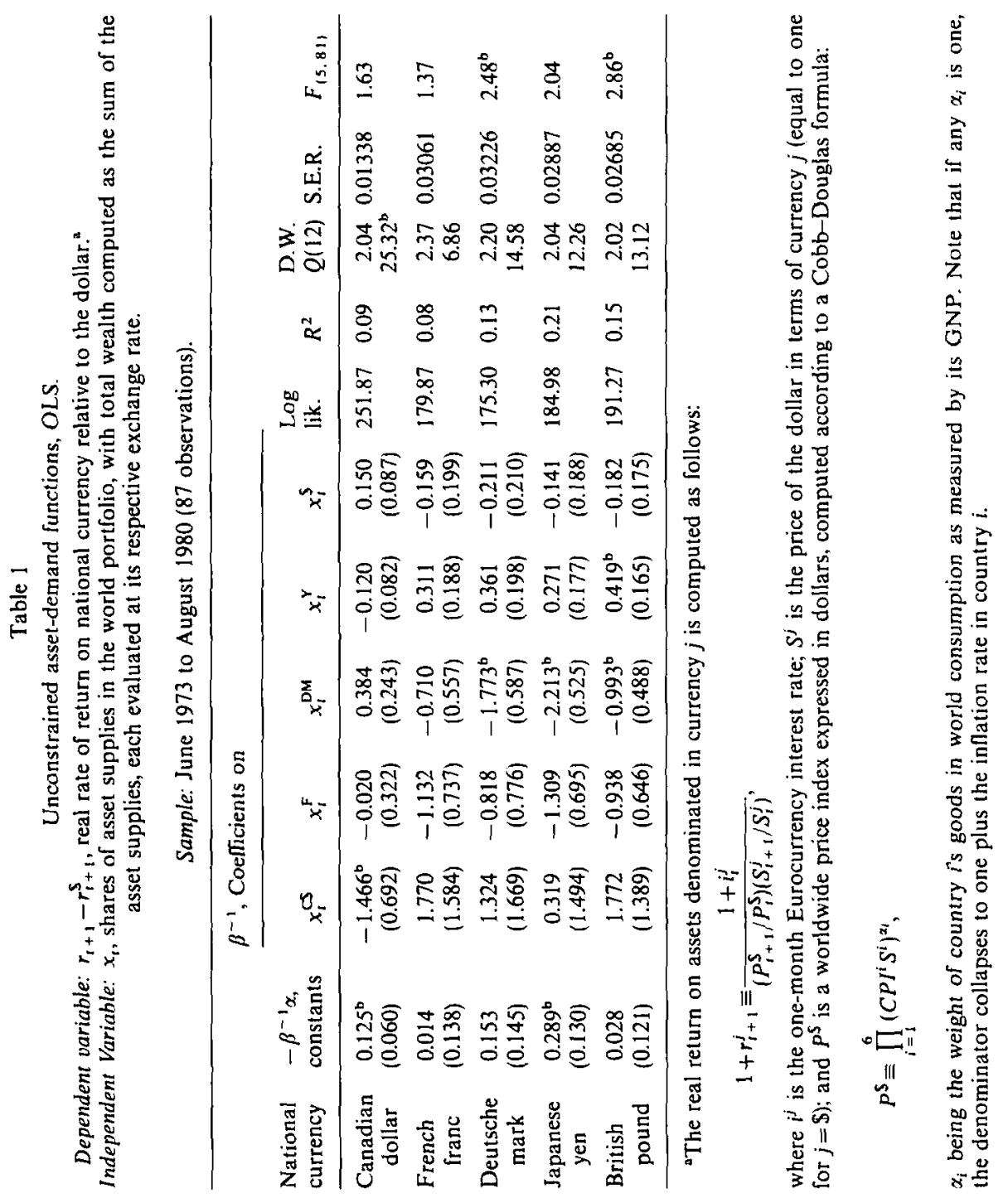


period real wealth. ${ }^{7}$ The reader familiar with Kouri (1977) or Dornbusch (1983), or with the general approach, which is standard in the C.APM literature, is urged to skip to the next section.

Let $W_{t}$ be real wealth. The investor must choose the vector of portfolio shares $x_{t}$ that he wishes to allocate to the various assets. End-of-period real wealth will be given by:

$$
\begin{aligned}
W_{t+1} & =W_{t}+W_{t} x_{t}^{\prime} r_{t+1}+W_{t}\left(1-x_{t}^{\prime} l\right) r_{t+1}^{s} \\
& =W_{t}\left[x_{t}^{\prime} z_{t+1}+1+r_{t+1}^{s}\right]
\end{aligned}
$$

where we have defined the vector of returns on the five assets relative to the dollar:

$$
z_{t+1} \equiv r_{t+1}-t r_{t+1}^{s}
$$

The expected value and variance of end-of-period wealth (5), conditional on current information, are as follows:

$$
\begin{aligned}
& E_{t} W_{t+1}=W_{t}\left[x_{t}^{\prime} E_{t} z_{t+1}+1+E_{t} r_{t+1}^{s}\right] \\
& V_{t} W_{t+1}=W_{t}^{2}\left[x_{t}^{\prime} \Omega x_{t}+V_{t} r_{t+1}^{s}+2 x_{t}^{\prime} \operatorname{cov}_{t}\left(z_{t+1}, r_{t+1}^{s}\right)\right]
\end{aligned}
$$

where we have defined the variance-covariance matrix of relative returns:

$$
\Omega \equiv E_{t}\left(z_{t+1}-E_{t} z_{t+1}\right)\left(z_{t+1}-E_{t} z_{t+1}\right)^{\prime}
$$

The hypothesis is that investors maximize a function of the expected value and variance:

$$
F\left[E_{t}\left(W_{t+1}\right), V_{t}\left(W_{t+1}\right)\right]
$$

We differentiate with respect to $x_{t}$ :

$$
\begin{aligned}
& \frac{\mathrm{d} F}{\mathrm{~d} x_{t}}=F_{1} \frac{\mathrm{d} E_{t} W_{t+1}}{\mathrm{~d} x_{t}}+F_{2} \frac{\mathrm{d} V_{t} W_{t+1}}{\mathrm{~d} x_{t}}=0, \\
& F_{1} W_{t}\left[E_{\mathrm{t}} z_{t+1}\right]+F_{2} W_{t}^{2}\left[2 \Omega x_{t}+2 \operatorname{cov}_{t}\left(z_{t+1}, r_{t+1}^{S}\right)\right]=0 .
\end{aligned}
$$

We define the coefficient of relative risk-aversion $\rho \equiv-W_{1} 2 F_{2} / F_{1}$, which is

\footnotetext{
${ }^{7}$ The assumption that returns are normally distributed is sufficient to imply that investors look only at the mean and variance. The normality assumption might be justified by an appeal to a continuous-time diffusion process observed at discrete intervals. In any case it is necessary to assume some specific distribution for the maximum likelihood estimation.
} 
assumed constant. ${ }^{8}$ Then we have our result:

$$
E_{t} z_{t+1}=\rho \operatorname{cov}_{t}\left(z_{t+1}, r_{t+1}^{s}\right)+\rho \Omega x_{t} .
$$

This equation is a linear relationship between the expected relative returns and the asset shares, as was eq. (2). The coefficient matrix, which we previously called $\beta^{-1}$, is now seen to be $\rho \Omega$, and the intercept vector, $-\beta^{-1} \alpha$, is now seen to be $\rho \operatorname{cov}_{t}\left(z_{t+1}, r_{t+1}^{s}\right)$. For economic intuition, we invert (6) to solve for the portfolio shares, the form analogous to (1):

$$
x_{t}=-\Omega^{-1} \operatorname{cov}_{t}\left(z_{t+1}, r_{t+1}^{S}\right)+(\rho \Omega)^{-1} E_{t} z_{t+1} .
$$

The asset demands consist of two parts. The first term represents the 'minimum-variance' portfolio. If an investor is extremely risk-averse $(\rho=\infty)$, the investor will hold the minimum-variance portfolio. For example, suppose he views the dollar as a safe asset, which requires not only that he consume only U.S. goods but also that U.S. prices are non-stochastic when expressed in terms of dollars. Then his minimum-variance portfolio is zero in each of the other five assets. The second term represents the 'speculative' portfolio. A higher expected return on a given asset induces investors to hold more of that asset than is in the minumum-variance portfolio, to an extent limited only by the degree of risk-aversion and the uncertainty of the return.

\section{Estimation of asset-demand functions constrained to be optimizing}

In this section we estimate the system (4) subject to the constraint that we found in the last section to be an implication of mean-variance optimization:9.10 $\beta^{-1}=\rho \Omega$. The key insight is that $\Omega$ is precisely the variance-covariance matrix of the error term: $\Omega \equiv E_{t} \varepsilon_{t+1} \varepsilon_{t+1}^{\prime}$. Imposition of a constraint between coefficients and variances, as opposed to a constraint

${ }^{8}$ The utility function will have a constant Arrow-Pratt coeflicient of relative risk-aversion if it is exponential in form:

$$
U(W)=\frac{1}{\gamma} W^{\gamma}, \text { where } \rho=1-\gamma
$$

[The solution to the one-period maximization problem considered here will be the correct solution to the general intertemporal maximization problem, if the utility function is further restricted to the logarithmic form, the limiting case as $\gamma$ goes to zero, which implies $\rho=1$, or if events occurring during the period are independent of the expected returns that prevail in the following period. See Merton (1973, pp. 877-878) or Fama (1970).]

${ }^{9}$ We do not impose the other constraint,

$$
\beta^{-1} \alpha=\rho \operatorname{cov}_{1}\left(z_{1+1}, r_{i+1}^{S}\right)
$$

because it is not feasible to do so econometrically. The constraint offers only five overidentifying restrictions anyway, whereas we already have twenty-five from our constraint on the coefficient matrix (twenty-four when $\rho$ is not constrained).

${ }^{10}$ An alternative approach would be to derive the maximizing system in terms of six absolute 
among coefficients, is unusual in econometrics, and requires maximum likelihood estimation. ${ }^{11}$ The appendix derives the first-order conditions for the maximization of the likelihood function and describes the program used.

If the aim, under the a priori constraint of mean-variance optimization, is to use the information to get the most efficient possible estimates of the parameters, then one might wish to impose not only the constraint that the coefficient matrix is proportional to the variance-covariance matrix $\Omega$, but to impose as well an a priori value for the constant of proportionality, which is the constant of relative risk aversion $\rho$. De Macedo (1980) and Krugman (1981) refer to the 'Samuelson presumption' that $\rho=2.0$. Table 2 reports the estimated parameters for the case $\rho=2.0$. The results look quite different from those in table $1 .{ }^{12}$ If one believes in the constraints, then the difference is simply the result of more efficient estimates. One would have to invert the coefficient matrix in order to recover the original $\beta$ matrix and see which assets are close substitutes for which other assets.

But we have chosen in this paper to emphasize the use of our technique to test the hypothesis of mean-variance optimization, rather than the use of the technique to impose the hypothesis. The log-likelihood for the estimates in table 2 is 1057.05 , a decrease from the unconstrained log-likelihood 1086.49. In other words, the fit has worsened considerably. Twice the difference is 59.0 , which is above the 5 percent critical level of 37.7. This constitutes a clear rejection of the optimization hypothesis.

returns, rather than five relative returns:

$$
\left[\begin{array}{c}
r_{t+1} \\
\cdots \\
r_{t+1}^{s}
\end{array}\right]=r_{1}^{0}\left[\begin{array}{c}
1 \\
\cdots \\
1
\end{array}\right]+\rho \Sigma\left[\begin{array}{c}
x_{t} \\
\cdots \\
1-x_{t}^{t}
\end{array}\right]+u_{t+1},
$$

where $\Sigma$ is the variance-covariance matrix of the errors $u_{t+1}$ made in predicting the absolute returns $r_{t+1}$, as opposed to the errors $\varepsilon_{t+1}$ made in predicting the relative returns $z_{t+1}$. The advantage would be that becase $\Sigma$ is six-by-six, we would have more overidentifying restrictions. The disadvantage is that the intercept term $\left(r^{\circ} \equiv \lambda W / F_{1}\right.$, where $\lambda$ is the Lagrangian shadow-price of wealth), though constant across equations, is not constant across time. A separate value of $r_{1}^{0}$ could be estimated for each point in time, but the large-sample properties of such an estimator are unclear. Subtracting the last row from each of the others eliminates $r_{1}^{0}$. Collecting terms in $x_{\text {, }}$ then restores us to eq. (6). For example, the first entry, $\left.\Sigma_{D M D M S}-\Sigma_{D M S}-\Sigma_{D M S}-\Sigma_{S S}\right)$, is the same as the first entry in $\Omega$. The lost row of $\Sigma$ seems a small price to pay.

${ }^{1}$ 'The idea of estimating asset-demand equations by drawing the link between the matrix of coefficients of the expected returns and the variance-covariance matrix of the actual returns is not entirely new. See, for example, Parkin (1970) and Wills (1979).

${ }^{12}$ The estimates in table 2 appear implausibly low. For example, a shift of 1 percent of the portfolio from U.S. dollars to Canadian dollars raises the expected relative returns that Canadian assets must pay by only 0.00037 percent $(0.037$ basis points)! The low magnitude of the coeflicients is an artifact of the mean-variance optimization hypothesis, as Krugman (1981) points out, not of the estimation procedure. The reader is invited to take his own estimates of the coeflicient of relative risk-aversion and the variance of the exchange rate and note how small their product is. The fact that such calculations give estimates of the coefficient that are very different than those in table 1 , is of course the reason that our test rejects the constraint of mean-variance optimization. 
Table 2

Constrained asset-demand functions, MLE.

\begin{tabular}{|c|c|c|c|c|c|c|}
\hline & ample: June & 73 to $A u$ & ust 1980 ( & 7 observa & ions). & \\
\hline & & $\beta^{-1}$ cons & rained to & $o \Omega$, with $f$ & $=2.0$ & \\
\hline $\begin{array}{l}\text { National } \\
\text { currency }\end{array}$ & Constants & $x_{t}^{c S}$ & $x_{i}^{F}$ & $x_{t}^{\text {DM }}$ & $x_{i}^{Y}$ & $x_{t}^{\mathfrak{f}}$ \\
\hline $\begin{array}{c}\text { Canadian } \\
\text { dollar }\end{array}$ & -0.00103 & 0.00037 & 0.00010 & 0.00021 & 0.00002 & 0.00009 \\
\hline $\begin{array}{l}\text { French } \\
\text { franc }\end{array}$ & 0.00140 & 0.00010 & 0.00188 & 0.00169 & 0.00099 & 0.00100 \\
\hline $\begin{array}{l}\text { Deutsche } \\
\text { mark }\end{array}$ & 0.00050 & 0.00021 & 0.00169 & 0.00223 & 0.00106 & 0.00107 \\
\hline $\begin{array}{c}\text { Japanese } \\
\text { yen }\end{array}$ & 0.00193 & 0.00002 & 0.00099 & 0.00106 & 0.00196 & 0.00081 \\
\hline $\begin{array}{l}\text { Pound } \\
\text { sterling }\end{array}$ & 0.00211 & 0.00009 & 0.00100 & 0.00107 & 0.00081 & 0.00158 \\
\hline
\end{tabular}

Log-likelihood $=1057.05$.

See table 1 for definitions of variables.

Perhaps 2.0 is not the correct value for the constant of risk-aversion $\rho$. We used the MLE program to find simultaneously the values of $\rho$ and $\Omega$ that maximize the likelihood. The log-likelihood at this point is 1057.96. (The MLE estimate of $\rho$ is -67.0 !) The value of $\rho$ makes almost no difference; we are still able to reject the hypothesis easily.

\section{Conclusions}

The theory of expected utility maximization, and in particular the simple framework of mean-variance optimization, is a very attractive way to bring more structure to the problem of asset-demand functions. The reader who is a priori inclined to accept that framework can view the numbers reported in table 2 as efficient estimates of the parameters in an international assetdemand function. The estimates are efficient because they use the information that, if investors indeed optimize, the coefficient matrix should be proportional to the error variance-covariance matrix. At the same time, the estimates can be argued to be superior to those in previous studies of the optimal portfolio because they use data on asset supplies and thus allow expected real returns to change from period to period.

However, the primary aim of this paper is to test explicitly the validity of the hypothesis of mean-variance optimization. The likelihood ratio test 
rejects the constraints imposed by the hypothesis. Thus, if we are to believe these results, the unconstrained parameter estimates reported in table 1, as imprecise as they are, are the best we can do.

How could investors fail to optimize with respect to the mean and variance of their real wealth? It is possible that they are simply not sophisticated enough. The literature on equity markets, for example, cannot be said to have found good empirical evidence for the CAPM theory. ${ }^{13}$ Of course it is possible that agents are rational, but optimize subject to constraints such as imperfect capital markets. A corporation may use as its measure of risk the variance of its own dollar profits, as opposed to the covariance with the market portfolio that the finance theory says it should use; and yet this may be rational if the corporation finances its projects internally and has to pay a penalty whenever an unexpected fall in earnings forces it to borrow externally. The same could be true of an individual. ${ }^{14}$

On the other hand, investors may be too sophisticated to optimizc (mercly) with respect to the mean and variance of their real end-of-period wealth. Stulz (1981), Hodrick (1981), and Hansen and Hodrick (1983) argue that investors maximize a more complicated intertemporal utility function. Unfortunately, their theoretical results are not as conducive to empirical testing as is the one-period mean-variance framework. ${ }^{15}$

The theory tested in this paper is one commonly discussed in the literature. The theory requires many assumptions: one-period expected utility maximization, a normal distribution for underlying returns, a constant variance-covariance matrix,${ }^{16}$ constant relative risk-aversion, homogeneous investors, rational expections, asset supplies that are properly measured from variables like government debt and foreign exchange intervention, and

\footnotetext{
${ }^{13}$ See, for example, Roll (1977) and the references cited there.

${ }^{14}$ If optimizing residents of different countries consume different baskets of goods, then they will use the variances of different quantities to measure risk, and the aggregation in this paper will be invalid. As in Frankel (1982b), we can disaggregate according to seven areas of residence: the six countries whose currencies are used here, and the rest of the world. Residents of each area are assumed to evaluate returns in terms of a weighted average of the six countries' prices, with prices assumed non-stochastic when denominated in the currency of the producing country and weights determined by that area's consumption shares. A likelihood ratio test then again rejects the constraint of mean-variance optimization. The likelihoods are 1043 unconstrained and 987 constrained with $\rho=2.0$. We are indebted to Tony Rodrigues for these calculations.

${ }^{15}$ However, if the coefficient of risk-aversion $\rho$ is close to 1.0, then the intertemporal complications vanish, as mentioned in footnote 8 . As a further bonus, the need to distinguish among investors according to their consumption basket, discussed in footnotes 5 and 14 , also vanishes. [See Adler and Dumas (1983) or Krugman (1981).] The likelihood ratio test, not surprisingly, also rejects the mean-variance optimization hypothesis when $\rho$ is constrained to 1.0 .

${ }^{16}$ One might legitimately wonder how we can assume the second moments of the returns constant over time while criticizing earlier studies for assuming the first moments constant over time. Could shifts in the variance-covariance matrix explain our results? Arnold (1983) uses our technique with the sample period divided in four subperiods to allow the variance-covariance matrix to change over time. He obtaines the same answer we do: a rejection of the constraint of mean-variance optimization.
} 
perfect capital markets. The failure of any one of these assumptions would explain the test result, the rejection of the theory.

\section{Acknowledgements}

This is a slightly revised version of NBER Working Paper No. 1051, December 1982. We would like to thank Paul Ruud for making available his Maximum Likelihood Estimation program, and Robert Hodrick and Steven Kohlhagen for comments and suggestions. We would also like to thank the Institute of Business and Economic Research at U.C. Berkeley, and the National Science Foundation for research support under grant numbers SES8007162 and SES-8218300.

\section{Appendix}

The parameters of the model were estimated by a maximum likelihood routine based on Berndt, Hall, Hall and Hausman's (1974) maximizing algorithm for non-linear models. The program makes use of the likelihood function, and its first derivatives. The $\log$ of the likelihood, under the normality assumption, is

$$
L=-\frac{G T}{2} \log (2 \pi)-\frac{T}{2} \log |\Omega|-\frac{1}{2} \sum_{t=1}^{T} \varepsilon_{t+1}^{\prime} \Omega^{-1} \varepsilon_{t+1},
$$

where

$$
\begin{aligned}
\varepsilon_{t+1} & =z_{t+1}-E_{t} z_{t+1} \\
& =z_{t+1}-c-\rho \Omega x_{t}
\end{aligned}
$$

and $G$ is the number of equations (five) and $T$ is the number of observations (eighty-seven).

In standard econometric problems the symmetry of the variancecovariance matrix $\Omega$ can safely be ignored in deriving the first-order conditions, because the $i j$ th element and the $j i$ th element of $\Omega$ enter the likelihood function symmetrically. In our problem, this is not true because of the restriction that $\Omega$ be proportional to the coefficient matrix, so care must be taken to allow properly for the symmetry. First, we derive $\partial L / \partial \Omega$ for an arbitrary (non-symmetric) $\Omega$ :

$$
\begin{aligned}
\frac{\partial L}{\partial \Omega} & =-\frac{T}{2} \frac{\partial \log |\Omega|}{\partial \Omega}-\frac{1}{2} \sum_{t=1}^{T} \frac{\partial \varepsilon_{t+1}^{\prime} \Omega^{-1} \varepsilon_{t+1}}{\partial \Omega} \\
& =-\frac{T}{2} \Omega^{\prime-1}+\frac{1}{2} \sum_{t=1}^{T}\left[\Omega^{\prime-1} \varepsilon_{t+1} \varepsilon_{t+1}^{\prime} \Omega^{\prime-1}+\rho\left(\Omega^{-1} \varepsilon_{t+1}+\Omega^{\prime-1} \varepsilon_{t+1}\right) x_{t}^{\prime}\right]
\end{aligned}
$$


Now, imposing symmetry, we let

$$
Q=\left[q_{i j}\right]=-\frac{T}{2} \Omega^{-1}+\frac{1}{2} \sum_{t=1}^{T}\left[\Omega^{-1} \varepsilon_{t+1} \varepsilon_{t+1}^{\prime} \Omega^{-1}+2 \rho \Omega^{-1} \varepsilon_{t+1} x_{t}^{\prime}\right]
$$

Then, if $\omega_{i j}$ is the $i j$ th element of $\Omega$,

$$
\partial L / \partial \omega_{i i}=q_{i i}
$$

and

$$
\partial L / \partial \omega_{i j}=q_{i j}+q_{j i}, \quad i \neq j
$$

We also have

$$
\partial L / \partial \rho=\sum_{t=1}^{T} \varepsilon_{t+1}^{\prime} x_{t}
$$

and

$$
\partial L / \partial c=\sum_{t=1}^{T} \Omega^{-1} \varepsilon_{t+1}
$$

where $\Omega$ has been assumed symmetric.

\section{Acknowledgements}

This is a slightly revised version of NBER Working Paper No. 1051, December 1982. We would like to thank Paul Ruud for making available his Maximum Likelihood Estimation program, and Robert Hodrick and Steven Kohlhagen for comments and suggestions. We would also like to thank the Institute of Business and Economic Research at U.C. Berkeley, and the National Science Foundation for research support under grant numbers SES8007162 and SES-8218300.

\section{References}

Adler, Michael and Bernard Dumas, 1976, Portfolio choice and the demand for forward exchange, American Economic Review 66, 332-339.

Adler, Michael and Bernard Dumas, 1983, International portfolio choice and corporation finance: A survey, Journal of Finance 38, 925-984.

Arnold, Bruce, 1983, Variable coefficients and the mean-variance optimization hypothesis: Continuing the search for the exchange risk premium (Princeton University, Princeton, N.J.).

Berndt, E.K., B.H. Hall, R.E. Hall and J.A. Hausman, 1974, Estimation and inference in nonlinear structural models, Annals of Economic and Social Measurement 3, 635-665.

Cornell, Bradford and J.K. Dietrich, 1978, The efficiency of the market for foreign exchange under floating exchange rates, Review of Economics and Statistics 60, 111-120.

de Macedo, Jorge, 1982, Portfolio diversification across currencies, in: Richard Cooper et al., eds., The international monetary system under flexible exchange rates (Ballinger, Cambridge). 
de Macedo, Jorge, J. Goldstein and D. Meerschwam, 1982, International portfolio diversification: Short-term linancial assets and gold, NBER conference, Bellagio, Italy: in: John Bilson and Richard Marston, eds., Exchange rate theory and policy (University of Chicago Press, Chicago) forthcoming.

Dooley, Michael and Peter Isard, 1983. The portfolio-balance model of exchange rates and some structural estimates of the risk premium. International Monetary Fund Staff Papers 30.683702.

Dornsbusch, Rudiger, 1980, Exchange rate economics: Where do we stand?. Brookings Papers on Economic Activity 1, 143-194.

Dombusch, Rudiger, 1983, Exchange risk and the macroeconomics of exchange rate determination, in: R. Hawkins, R. Levich and C. Wihlborg, eds., The internationalization of financial markets and national economic policy (JAI Press, Greenwich).

Dumas, Bernard, 1982. Discussion of international portfolio diversification: Short-term financial assets and gold, NBER conference, Bellagio, Italy; in: John Bilson and Richard Marston. eds., Exchange rate theory and policy (University of Chicago Press, Chicago).

Engel, Charles, 1982, Testing for the absence of expected real profits from forward market speculation (University of California, Berkeley); forthcoming in Journal of International Economics.

Fama, Eugene, 1970, Multi-period consumption-investment decisions, American Economic Review 60, 163-174.

Fama, Eugene and Andre Farber, 1979, Money, bonds and foreign exchange, American Economic Review 69, 639-649.

Frankel, Jeffrey, 1979, The diversifiability of exchange risk, Journal of International Economics 9, 379-393.

Frankel, Jeffrey, 1982a, A test of perfect substitutability in the foreign exchange market, Southern Economic Journal 48, 406-416.

Frankel, Jeffrey, 1982b, In search of the exchange risk premium: A six-currency test assuming mean-variance optimization, Journal of International Money and Finance 1, 255-274.

Frankel, Jeflrey, 1983, Estimation of portfolio-balance functions that are mean-variance optimizing: The mark and the dollar, European Economic Review 23, 315-327.

Frenkel, Jacob and Assaf Razin, 1980, Stochastic prices and tests of efficiency of foreign exchange markets, Economic Letters 6, 165-170.

Garman, Mark and Steven Kohlhagen, 1980, Infation and foreign exchange rates under production and monetary uncertainty (University of California, Berkeley).

Grauer, F.L.A., R.M. Litzenberger and R.E. Stehle, 1976, Sharing rules and equilibrium in an international capital market under uncertainty, Journal of Financial Economics 3, 233-256.

Hansen, Lars and Robert Hodrick, 1983, Risk-averse speculation in the forward foreign exchange market: An econometric analysis of linear models, in: Jacob Frenkel, ed., Exchange rates and international macroeconomics (University of Chicago Press, Chicago).

Hodrick, Robert, 1981, International asset pricing with time-varying risk premia, Journal of International Economics 11, 573-577.

Kasliwal, Pari, 1982, The pattern of trade flows, real risk and exchange rate determination, Ph.D. dissertation, (University of California, Los Angeles).

Kouri, Pentti, 1976, The determinants of the forward premium, IlES Seminar Paper 62 (University of Stockholm, Stockholm, Sweden).

Kouri, Pentti, 1977, International investment and interest rate linkages under flexible exchange rates, in: Robert Aliber, ed., The political economy of monetary reform (Macmillan \& Company, London).

Kouri, Pentti and Jorge de Macedo, 1978, Exchange rates and the international adjustment process, Brookings Papers on Economic Activity 1, 111-150.

Krugman, Paul, 1981, Consumption preferences, asset demands, and distribution effects in international financial markets, Working Paper No. 651 (National Bureau of Economic Research, Cambridge).

Merton, Robert, 1973, An intertemporal capital asset pricing model, Econometrica 41, 867-887.

Parkin, Michael, 1970, Discount house portfolio and debt sclection, Review of Economic Studies 37, 469-497.

Roll, Richard, 1977, A critique of the asset pricing theory's test: Part 1: On past and potential testability of the theory, Journal of Financial Economics 4, 129-176. 
Roll, Richard, and Bruno Solnik, 1977, A pure foreign exchange asset pricing model, Journal of International Economics 7, 161-180.

Solnik, Bruno, 1974, An equilibrium model of the international capital market, Journal of Economic Theory 8, 550-624.

Stulz, Rene, 1981, A model of international assel pricing, Journal of Financial Economics 9, $383-406$.

von Furstenberg, George, 1981, Incentives for international currency diversification by U.S. financial investors, International Monetary Fund Staff Papers 28, 477-494.

Wills, Hugh, 1979, Inferring expectations (London School of Economics, London). 